\title{
BENEFÍCIOS DA CINESIOTERAPIA LABORAL PARA SERVIDORES PÚBLICOS DO SETOR JURÍDICO
}

\author{
Acácio José Lustosa Mendes ${ }^{1}$ \\ Bruna do Rocio Oliveira ${ }^{2}$ \\ Jenifer Letícia Lourenço Santos ${ }^{3}$ \\ Rubia Bayerl ${ }^{4}$ \\ Tatiane Hovoruski Pereira ${ }^{5}$ \\ Ana Carolina Brandt de Macedo ${ }^{6}$ \\ Ariani Cavazzani Szkudlarek ${ }^{7}$ \\ Rubneide Barreto Silva Gallo ${ }^{8}$ \\ Talita Gianello Gnoato Zoltz ${ }^{9}$ \\ Arlete Ana Motter ${ }^{10}$
}

RESUMO: Introdução: A cinesioterapia laboral diz respeito a exercícios físicos realizados durante a jornada de trabalho, idealizados para compensar os movimentos repetitivos, a escassez de movimentação, ou mesmo compensar as posturas assumidas durante o período de trabalho. Metodologia: Realizou-se um estudo transversal, exploratório e descritivo, desenvolvido entre agosto a novembro de 2018, em Curitiba/PR. Participaram servidores e estagiários da Procuradoria Geral do Estado do Paraná (PGE), que concordaram com a pesquisa assinando o Termo de Consentimento Livre e Esclarecido (TCLE). Foram realizadas 11 intervenções de Cinesioterapia Laboral, uma vez por semana, intercaladas por Orientações Individuais nos Postos de Trabalho. Os participantes foram avaliados e reavaliados com 4 questionários: autoral, Nórdico, Burnout e Inventário de Qualidade de Vida (IQV). Resultados e discussão: Houve predomínio do sexo feminino (89,2\%). No questionário de Burnout não houve melhora quanto aos quesitos de Despersonalização e Exaustão Emocional, no questionário Nórdico foi identificado uma melhora nas dores referidas no pescoço e na parte inferior das costas, enquanto no IQV foi identificado que a qualidade de vida era boa no pré e pós intervenção nos quadrantes social, profissional e afetivo, porém foi identificado um grande índice de insucesso no quadrantes de saúde. Conclusão: A Cinesioterapia Laboral proporciona diversos benefícios tanto aos participantes quanto às empresas. As orientações individuais nos postos de trabalho proporcionam aos trabalhadores um meio de realizar suas atividades laborais cotidianas de modo mais confortável, com menos riscos biomecânicos, contribuindo para o bem estar no trabalho.

Palavras-chave: Promoção e prevenção; cinesioterapia laboral; ergonomia; exercícios físicos; fisioterapia.

\footnotetext{
${ }^{1}$ Universidade Federal do Paraná

2 Universidade Federal do Paraná

${ }^{3}$ Universidade Federal do Paraná

${ }^{4}$ Universidade Federal do Paraná

${ }^{5}$ Universidade Federal do Paraná

${ }^{6}$ Universidade Federal do Paraná

${ }^{7}$ Universidade Federal do Paraná

${ }^{8}$ Universidade Federal do Paraná

${ }^{9}$ Universidade Federal do Paraná

10 Universidade Federal do Paraná
} 
Introducción: La cinesioterapia laboral se refiere a ejercicios físicos realizados durante la jornada de trabajo, idealizados para compensar los movimientos repetitivos, la escasez de movimiento, o incluso compensar las posturas asumidas durante el período de trabajo. Metodología: Se realizó un estudio transversal, exploratorio y descriptivo, desarrollado entre agosto a noviembre de 2018, en Curitiba / PR. Participaron servidores y pasantes de la Procuraduría General del Estado de Paraná (PGE), que concordaron con la investigación firmando el Término de Consentimiento Libre y Esclarecido (TCLE). Se realizaron 11 intervenciones de Cinesioterapia Laboral, una vez por semana, intercaladas por Orientaciones Individuales en los puestos de trabajo. Los participantes fueron evaluados y reevaluados con 4 cuestionarios: autoral, Nórdico, Burnout e Inventario de Calidad de Vida (IQV). Resultados y discusión: Hubo predominio del sexo femenino (89,2\%). En el cuestionario de Burnout no hubo mejoría en cuanto a los requisitos de Despersonalización y Extracción Emocional, en el cuestionario Nórdico se identificó una mejora en los dolores referidos en el cuello y en la parte inferior de la espalda, mientras que en el IQV fue identificado que la calidad de vida era buena en el pre y, después de la intervención en los cuadrantes social, profesional y afectivo, pero fue identificado un gran índice de fracaso en los cuadrantes de salud. Conclusión: La Cinesioterapia Laboral proporciona diversos beneficios tanto a los participantes como a las empresas. Las orientaciones individuales en los puestos de trabajo proporcionan a los trabajadores un medio para realizar sus actividades laborales cotidianas de manera más confortable, con menos riesgos biomecánicos, contribuyendo al bienestar en el trabajo.

Palabras clave: Promoción y prevención; cinesioterapia laboral; la ergonomía; ejercicios físicos; fisioterapia.

Introduction: Occupational kinesiotherapy refers to physical exercises performed during the work day, designed to compensate for repetitive movements, the lack of movement, or even compensate for the postures assumed during the work period. Methodology: A crosssectional, exploratory and descriptive study was carried out between August and November of 2018, in Curitiba / PR. Servants and trainees from the Attorney General's Office of the State of Paraná (PGE), who agreed to the study signed the Free and Informed Consent Term (TCLE). Eleven interventions of Occupational Kinesiotherapy were carried out once a week, interspersed by Individual Orientations in the Workplaces. Participants were evaluated and re-evaluated with 4 questionnaires: author, Nordic, Burnout and Quality of Life Inventory (IQV). Results and discussion: There was a predominance of females (89.2\%). In the Burnout questionnaire, there was no improvement in the aspects of Depersonalization and Emotional Exhaustion. In the Nordic questionnaire, an improvement in the referred pains in the neck and lower back was identified, while in IQV it was identified that the quality of life was good in the pre- and post intervention in the social, professional and affective quadrants, but a great index of failure in the health quadrants was identified. Conclusion: Labor Kinesioterapia offers several benefits to both participants and companies. Individual job orientations provide workers with a means to perform their daily work activities more comfortably, with fewer biomechanical risks, and contribute to the well-being at work.

Palavras-chave: Promotion and prevention; labor kinesiotherapy; ergonomics; physical exercises; physiotherapy.

Revista Extensão em Foco, nº 20, Jan./Jul. (2020), p. 86 - 101. 


\section{INTRODUÇÃO}

A cinesioterapia laboral, originária da Polônia e praticada no Brasil desde 1973, consiste em exercícios físicos realizados durante a jornada de trabalho que tem por objetivo promover o lazer e melhorar a produtividade, entre outros benefícios (BITTENCOURT et al, 2014).

Os exercícios físicos são idealizados para compensar os movimentos repetitivos inerentes à atividade laboral cotidiana, a escassez de movimentação, ou mesmo compensar as posturas assumidas durante o período de trabalho que causam algum tipo de constrangimento físico (OLIVEIRA, 2007).

Com os novos modos de produção e intensificação do trabalho, decorrentes da revolução industrial e capitalismo, surgiram também às lesões e doenças relacionadas ao trabalho, desse modo, o fisioterapeuta vem atuando em empresas através da cinesioterapia laboral, com o objetivo de prevenir e minimizar problemas de saúde e consequentemente, melhorando a qualidade de vida dos trabalhadores (IACKSTET; GONÇALVES; SOARES, 2018).

Assim, ela atua como um método de prevenção e tratamento das Lesões por Esforços Repetitivos ou Distúrbios Osteomusculares Relacionados ao Trabalho (LER/DORT) e consiste em uma atividade física praticada no local de trabalho, de curta duração e contendo exercícios de alongamento, consciência corporal e relaxamento, de modo a compensar as estruturas corporais exigidas ao longo do trabalho (SANTOS et al, 2007; GOMES, 2017).

Dentre as afecções mais comuns, a lombalgia é a mais frequente, pois a região lombar acomoda maior carga de peso. A etiologia da dor lombar é multifatorial, ou seja, diversos aspectos podem influenciar, enfatizando a biomecânica, características individuais e fatores ocupacionais, como longos períodos na posição sentada antiergonômica (FREITAS et al., 2011). A longa permanência na postura sentada submeterá os músculos paravertebrais a uma tensão constante para manter o tronco ereto, e consequentemente, haverá perdas da flexibilidade do sistema locomotor, que acrescido de posturas inadequadas, serão fatores primordiais para o surgimento de problemas físicos associados à fadiga e sintomatologias de dor e desconforto (MORO e REIS, 2003).

Em relação aos benefícios, quando se adota a Cinesioterapia Laboral em uma empresa, envolve-se a coletividade, o que propicia, além das interações sociais, os benefícios físicos como a respiração, alongamento muscular, melhor oxigenação e circulação sanguínea, Revista Extensão em Foco, nº 20, Jan./Jul. (2020), p. 86 - 101. 
momentos de descontração e uma retirada momentânea dos insumos do trabalho. É uma pausa em que, apesar dos cargos exercidos, exerce a igualdade entre os participantes: seres humanos em busca de bem-estar, saúde e qualidade de vida no trabalho (AGUIAR et al., 2015). O benefício mais relatado é a melhora da dor e do desempenho no ambiente de trabalho, seguido da melhora da saúde, do bem-estar, redução do estresse e aumento da motivação. Sendo assim, diminui o índice de absenteísmo e afastamentos médicos (IACKSTET; GONÇALVES; SOARES, 2018; MOAZZAMI et al, 2016).

Portanto, o objetivo desse artigo é avaliar os benefícios da cinesioterapia laboral para servidores públicos do setor judiciário.

\section{METODOLOGIA}

Trata-se de um estudo transversal, exploratório e descritivo, desenvolvido de agosto a novembro de 2018, em Curitiba/PR. Participaram servidores e estagiários com vínculo empregatício à Procuradoria Geral do Estado do Paraná, que aceitaram voluntariamente participar da pesquisa (em todas as etapas) concordando e assinando o Termo de Consentimento Livre e Esclarecido.

Os critérios de inclusão na pesquisa foram: possuir vínculo empregatício com a repartição pública, devendo ocupar cargo efetivo ou temporário (estagiários), assinar o termo de consentimento livre e esclarecido (TCLE), responder todos os questionários no início e ao término do projeto, não estar realizando outra intervenção fisioterapêutica além do proposto no projeto e participar de no mínimo oito das onze intervenções.

Os critérios para a exclusão foram: possuir doença coronariana, responder aos questionários de maneira incompleta, não preenchimento dos questionários iniciais ou finais, não-concordância com o TCLE, assiduidade inferior a oito intervenções (FIGURA 1). 
Figura 1. Etapas seguidas no estudo para seleção e inclusão/exclusão dos participantes.

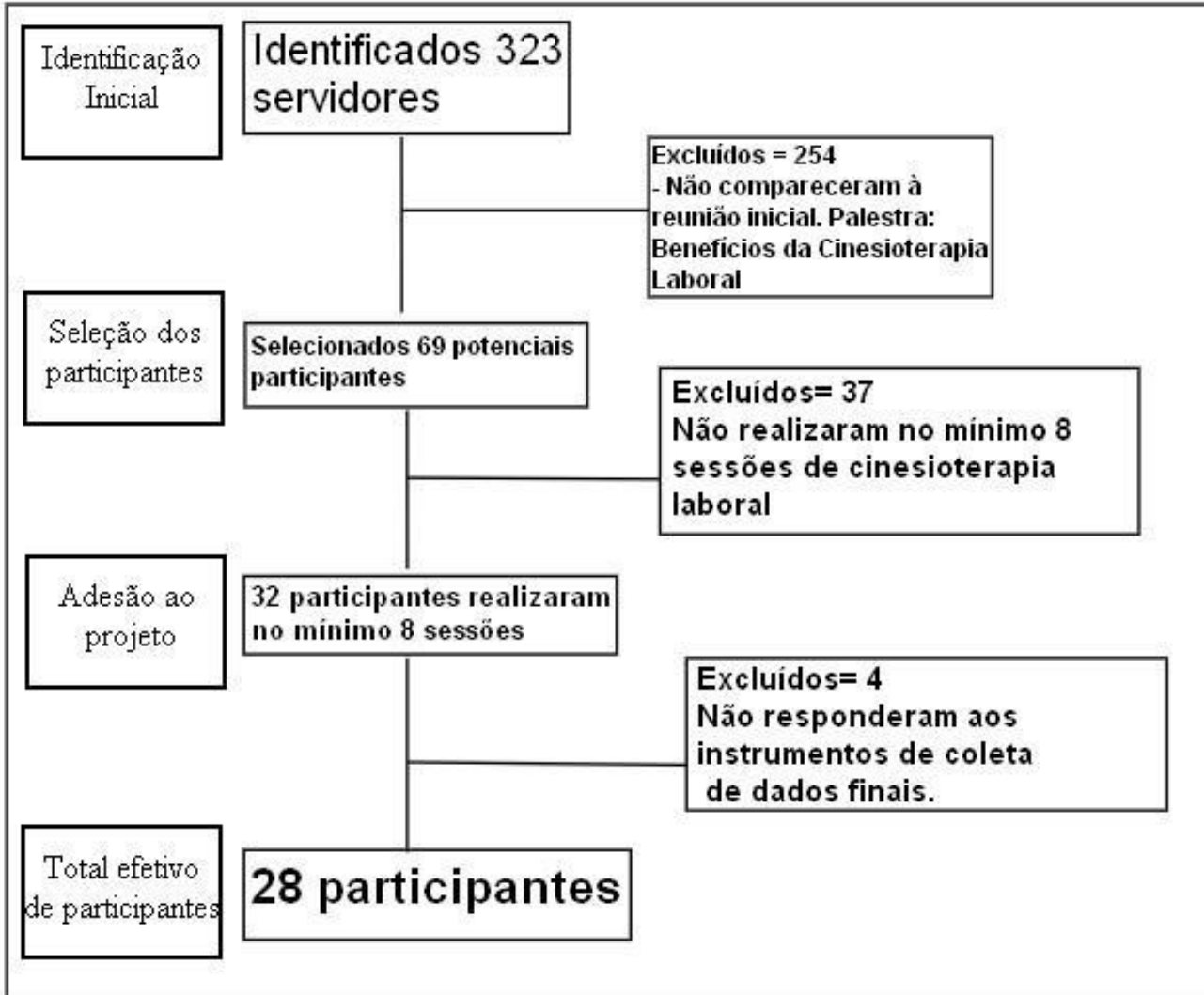

Os instrumentos utilizados para avaliação foram: Questionário Autoral para avaliar o perfil da população estudada, Questionário Nórdico, Maslach Burnout Inventory - Human Services Survey (MBI-HSS) versão em português e Inventário de Qualidade de Vida (IQV).

Foi desenvolvido pela equipe um questionário autoral, para avaliar as características ocupacionais e dados pessoais dos participantes da pesquisa, tais como: idade, sexo, escolaridade, tempo que está na ocupação, tempo que permanece sentado, se realiza pausas durante o trabalho, se já realizou cinesioterapia laboral, se sim, por quanto tempo e qual a sua percepção da prática.

Os sintomas osteomusculares autorreferidos através do Questionário Nórdico de Sintomas Osteomusculares que contém um conjunto de perguntas padronizadas que identificam queixas ou sintomas em grupos profissionais (FERNANDES et al., 2018).

O questionário de Burnout para avaliar a Síndrome de Burnout que é vista como um fenômeno psicossocial, uma resposta crônica aos estressores interpessoais ocorridos no ambiente de trabalho, é composta por três dimensões: exaustão emocional, despersonalização e baixa realização profissional (MALLMANN et al., 2009).

Revista Extensão em Foco, nº 20, Jan./Jul. (2020), p. 86 - 101. 
O Inventário de Qualidade de Vida (IQV) foi um instrumento desenvolvido por Lipp e Rocha (1995) baseado na ideia de que a qualidade de vida de uma pessoa é influenciada diretamente por seu nível de estresse. Ele é composto por quatro quadrantes (social, afetivo, profissional e de saúde) e serve para verificar como está a qualidade de vida dos participantes. É utilizada uma forma de pontuar cada pergunta e conforme os valores obtidos, conclui-se se há sucesso em cada uma dessas áreas/quadrantes. São 45 perguntas fechadas em que os avaliados respondem sim ou não (PINHEIRO; LIPP, 2009) conforme o estado que se encontram no momento (HELOANI, 2006). E, é considerada que uma boa qualidade de vida só é obtida se o sujeito apresentar sucesso nas quatro áreas/quadrantes (SOUZA, 2014). Há 10 itens em cada quadrante, exceto o quadrante saúde que contém 15 itens. O quadrante social avaliará como estão as relações sociais do participante; no afetivo avaliará a relação dar-receber afeto; no profissional avaliará a percepção do respondente quanto ao seu trabalho e no de saúde, procurará saber quais são os hábitos de vida e de saúde do respondente (ALVES, 2008).

Para convidar e incentivar a participação dos funcionários foi realizada uma reunião inicial, na qual foi explicado o que é a cinesioterapia laboral, os benefícios descritos na literatura, número de intervenções por semana, duração de cada intervenção, o tipo de exercício que seria desenvolvido, métodos utilizados para avaliação pré e pós intervenções e uma breve demonstração dinâmica de como seria a prática da cinesioterapia laboral.

Os participantes receberam a intervenção no seu próprio setor de trabalho, uma vez por semana, mas também receberam orientações para repetir os exercícios ao longo da semana. Foi aplicada a cinesioterapia laboral compensatória, relaxante e em dias alternados, exercícios resistidos utilizando faixas elásticas, dividida por regiões corporais. As práticas consistiram em 5 minutos de aquecimento prévio, 10 exercícios de alongamento com 2 repetições de 15 segundos cada e para finalizar, 5 minutos de relaxamento, totalizando 15 minutos por intervenção. A cada intervenção foi entregue um folder em cada setor, contendo todos os exercícios realizados para que sempre que pudessem, realizassem os exercícios.

Os exercícios são de rápida e fácil execução, direcionado ao ganho de flexibilidade para os músculos dos membros superiores, membros inferiores e tronco e diminuição das algias. Foram utilizados materiais como aparelhos de som/celulares para colocar músicas durante as intervenções e também faixas elásticas para a execução de alguns exercícios. Todo o programa de exercícios foi adaptado para o ambiente de trabalho.

Revista Extensão em Foco, nº 20, Jan./Jul. (2020), p. 86 - 101. 
Concomitantemente aos exercícios, foram realizadas as orientações individuais em cada posto de trabalho para aqueles que concordaram em receber as orientações. As orientações incluíram, posicionamento do computador em relação a janela e ao formato da mesa, uso de apoio para pés, altura do assento, altura do encosto, altura da mesa, uso de apoio para teclado, apoio para os braços da cadeira, mousepad, distância do teclado em relação ao operador, uso de todos os dedos para digitação, altura da tela, distância olho/tela e uso de suporte para leitura. Para finalizar o projeto, foi realizado uma comparação dos questionários aplicados no primeiro dia e após onze intervenções, para verificar se a prática da cinesioterapia laboral proporcionou diferenças na qualidade de vida e nos quadros álgicos dos servidores.

\section{RESULTADOS}

A pesquisa contou com um total de 28 participantes, os quais atenderam a todos os critérios de inclusão. Sendo trabalhadores do setor jurídico abrangeu Procuradores, Servidores, Contadores, Agentes de Execução, Auxiliares Administrativos e Estagiários, como apresentado no Gráfico 1. No pós intervenção foram identificados 9 participantes do sexo masculino $(32,2 \%)$ e 19 do sexo feminino (67,8\%), com idade média de 35,2 anos (variando entre 19 e 59), tempo médio de profissão de 8 anos. Trabalham em média 7 horas/dia, sendo que deste período passam, em média, 6 horas sentados. A escolaridade vai do ensino médio completo, graduandos de direito e ciências contábeis e com ensino superior completo, conforme expresso no Gráfico 2.

Gráfico 1: Categorias profissionais dos participantes

Revista Extensão em Foco, nº 20, Jan./Jul. (2020), p. 86 - 101. 




Gráfico 2: Escolaridade dos participantes

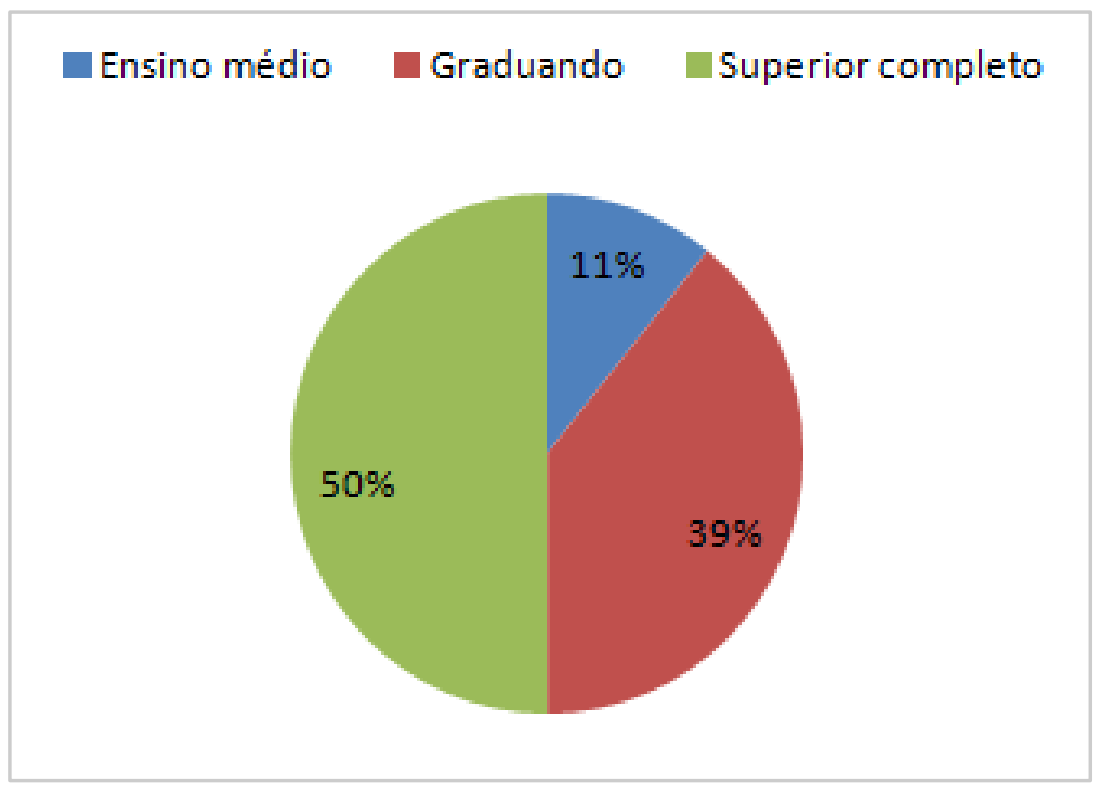

Foi avaliado também a forma que os trabalhadores realizavam suas tarefas, dinâmico ou estático, e foi identificado uma prevalência de trabalhadores que têm suas ocupações de forma estática $96,4 \%$ no pré intervenção, reduzindo para 89,2\% no pós intervenção.

Revista Extensão em Foco, nº 20, Jan./Jul. (2020), p. 86 - 101. 
Os resultados encontrados através do questionário Nórdico estão expressos na Tabela 1. O percentual descrito considerou as respostas afirmativas em relação ao total de participantes que realizaram as orientações e participaram da pesquisa.

TABELA 1 - QUESTIONÁRIO NÓRDICO

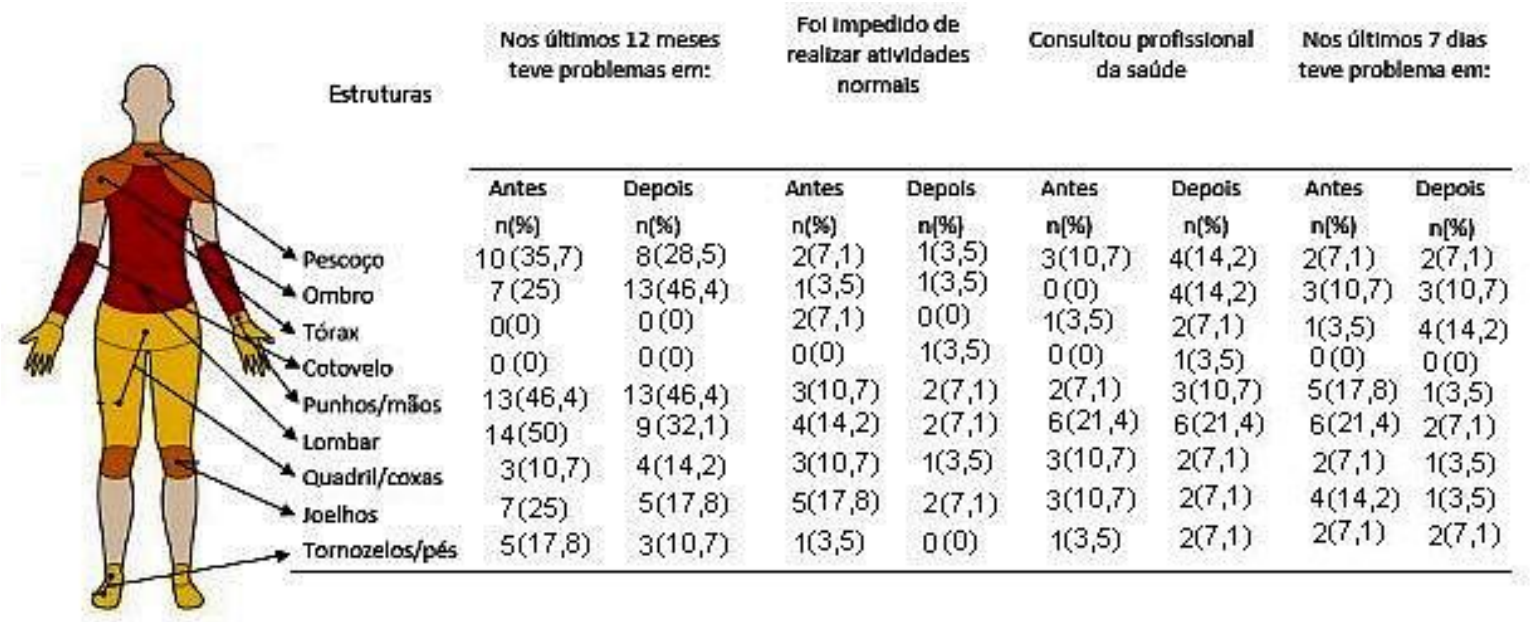

Os achados no questionário de Burnout seguem-se nos Gráfico 3, 4 e 5.

Gráfico 3: Resultados do Burnout quanto à exaustão profissional



Gráfico 4: Resultados do Burnout quanto à Realização Profissional

Revista Extensão em Foco, no 20, Jan./Jul. (2020), p. 86 - 101. 




Gráfico 5: Resultados do Burnout quanto à Despersonalização



No questionário Nórdico, inicialmente $59,52 \%$ dos avaliados apresentavam dor no pescoço e na parte inferior das costas, enquanto na reavaliação $42,85 \%$ apresentaram dor no pescoço e $53.57 \%$ na parte inferior das costas, a dor não desapareceu, no entanto, houve uma redução visível.

No questionário de qualidade de vida, foi identificado uma boa qualidade de vida no pré e no pós intervenção nos quadrantes social, afetivo e profissional, porém o quadrante de saúde houve um alto índice de insucesso. Os participantes da pesquisa apresentaram $87,71 \%$ de sucesso na área profissional, 75\% de sucesso no quadrante social e 67,85\% de sucesso na área afetiva, já na área da saúde houve $75 \%$ de insucesso. Nas orientações individuais, de 28 participantes, 16 receberam as análises, totalizando $57,1 \%$ de adesão.

Revista Extensão em Foco, nº 20, Jan./Jul. (2020), p. 86 - 101. 
Respostas como "diminuíram dores no corpo, ficou mais disposto para o trabalho"; "melhorou o humor, diminuiu o estresse, melhorou a relação com os colegas, e melhorou a qualidade de vida" foram respostas frequentes no questionário.

\section{DISCUSSÃO}

A pesquisa contou com a participação de servidores e estagiários considerados jovens (idade média de 35,2 anos), sendo a maioria do sexo feminino. A incidência de sintomatologia dolorosa neste grupo pode ocorrer pela diferença de composição corporal e da massa muscular do sexo feminino em relação ao sexo masculino, além de maior incidência de estresse, o que gera maior tensão muscular (MELO et al.,2013).

O tempo de profissão variou entre 2 meses à 37 anos e, relacionando com queixas álgicas pelo Questionário Nórdico, não percebeu-se correlações significativas entre o tempo de profissão e dores musculoesqueléticas. No entanto, segundo a literatura há uma relação proporcional do tempo de profissão com maiores índices de dores. Cardoso et al. (2009) por exemplo, verificaram a forte relação do tempo de ocupação em docentes com a maior ocorrência de distúrbios musculoesqueléticos e Maciel et al. (2006) também encontraram relação significativa entre tempo de ocupação e queixas de dores, em que 77,9\% dos profissionais da indústria têxtil com mais de seis meses de trabalho alegaram dor em mais de uma região corporal.

Neste estudo, o nível de escolaridade dos participantes era de 11 graduandos, 14 de nível superior completo e 3 do ensino médio. Relacionando a escolaridade com o Questionário Nórdico, percebeu-se que tiveram sintomas musculoesqueléticos: $81,81 \%$ dos graduandos; $78,57 \%$ dos que têm nível superior e 33,33\% dos que possuíam nível de escolaridade médio. O predomínio maior de sintomas naqueles que estão estudando, pode ter correlação com mais horas sentado e mais horas no uso do computador. Contrapondo os nossos resultados, Cardoso et al. (2009), constatou que os professores que possuíam o nível de escolaridade médio, apresentavam maior predomínio de dores nos membros inferiores em relação aos que tinham nível superior.

Em um estudo com objetivo de analisar o nível de estresse e a qualidade de vida de clérigos, Pinheiro \& Lipp (2009), com uma amostra de 74 participantes, 49 do sexo masculino e 25 do sexo feminino através da aplicação do IQV encontrou-se uma maior percepção de sucesso nas áreas afetivas, profissional e social, porém com significativa percepção de insucesso na área da saúde. Os achados do presente estudo reafirmam as Revista Extensão em Foco, nº 20, Jan./Jul. (2020), p. 86 - 101. 
pesquisas feitas por Pinheiro \& Lipp (2009), em que os quadrante social, profissional e afetivo apresentaram sucesso e o quadrante saúde apresentou insucesso Esses resultados, ilustram que o aspecto mais preocupante nos participantes é o relativo à saúde, o que condiz com o resultado do questionário Nórdico, no qual há queixas de desconforto e dor.

No presente estudo após a intervenção das 11 sessões de CL obteve-se melhoras nos sintomas musculoesqueléticos segundo o questionário nórdico, porém em relação ao questionário de Burnout não houve alteração. Considera-se a hipótese de que para obter melhores resultados no questionário de Burnout, talvez fosse necessário um período mais prolongado de intervenções, conforme o estudo de Santos (2017) que propôs a intervenção da CL em 18 sessões com resultados estatisticamente significativos na redução dos sintomas musculoesqueléticos da síndrome de Burnout dos participantes.

Com relação à adesão, o estudo na PGE iniciou com 69 potenciais participantes, havendo em média 50 participantes semanais, contudo apenas 28 deles entraram no estudo, visto que muitos não se encaixaram nos critérios de inclusão. Assim, $46,37 \%$ dessa população realizou 8 ou mais sessões de CL e, verificou-se que na maioria das vezes houve indisponibilidade de realizar a prática quando eram chamados pelo motivo de estarem atarefados naquele momento. Observou-se que houve uma adesão maior por parte dos estagiários, seguido pelos servidores e por último os procuradores. Algumas das hipóteses levantadas pela baixa adesão dos trabalhadores com cargos superiores é a sobrecarga de trabalho, a maior cobrança de prazos de seus afazeres e a inconstância da presença física no posto de trabalho, estes que muitas vezes não se encontravam na Procuradoria por estarem em compromissos externos. A baixa adesão na ginástica laboral foi estudada por Soares, Assunção e Lima (2006), em que os participantes relatam a falta de adesão principalmente por motivos pessoais em não querer fazer exposição física em frente aos demais colegas, ou por não coincidir o horário de pausa com o horário da ginástica ou por estarem realizando alguma tarefa importante no momento da chamada à ginástica, o que respalda com o observado em nossas intervenções.

As orientações individuais nos postos de trabalho são medidas importantes para reduzir as queixas osteomusculares, pois segundo Moazzami et al, (2016) o aprendizado postural, a mudança de hábitos e a reestruturação da disposição física do trabalho e trabalhador podem minimizar os constrangimentos músculo esqueléticos. As orientações de ajustes do mobiliário nos postos de trabalho e correções posturais foram realizadas após observações acerca das posturas e movimentos adotadas pelo participante Revista Extensão em Foco, nº 20, Jan./Jul. (2020), p. 86 - 101. 
observado. Os resultados da pesquisa foram positivos, pois além da aplicação de questionários e programa de intervenções, realizou-se essas ações educativas visando a reeducação da realização do trabalho.

A mudança de hábitos e sua manutenção surge como medida preventiva de distúrbios musculoesqueléticos, intervenções rápidas (até 10 minutos) costumam ser mais atrativas e eficazes que instruções complexas e de longa duração (acima de 40 minutos), conforme apresenta em seu estudo Madhwani e Nag (2017), levando a crer que as intervenções apresentaram efeitos positivos (Poblete; López, 2012). Nesse estudo, quando comparados os resultados pré e pós orientações pelo Nórdico, houve melhoras em relação à queixa de dor, formigamento ou dormência no pescoço e parte inferior das costas, com maior expressividade. Foi analisado que o grupo de pessoas que recebeu as orientações individuais nos postos de trabalho apresentou resultados mais positivos. Supõe-se que essa descoberta tenha relação direta com a forma adequada que os trabalhadores adotaram após as orientações.

De forma complementar ao programa de cinesioterapia laboral, as orientações ergonômicas realizadas apresentam-se como eficientes em relação aos segmentos que recebem maior sobrecarga durante a atividade laboral.

\section{CONCLUSÃO}

A Cinesioterapia Laboral proporciona diversos benefícios tanto aos participantes quanto às empresas. Pode-se notar essa afirmação ao avaliar o aspecto de percepção da Cinesioterapia Laboral no questionário autoral, onde os participantes descreviam como sentiam-se a respeito das intervenções. As orientações individuais nos postos de trabalho proporcionam aos trabalhadores um meio de realizar suas atividades laborais cotidianas de modo que possa contribuir positivamente com sua qualidade de vida e bem estar no trabalho. Conclui-se também que a Cinesioterapia Laboral juntamente com as orientações individuais proporcionam uma melhora no aspecto físico, como demonstrado nos resultados dos questionários. O estudo teve como limitações fatores como o tipo de função, sedentarismo, etnia, dentre outros. Acreditamos que os resultados obtidos são bastante relevantes e satisfatórios em relação à aplicação de nossas intervenções, mas possivelmente a análise de uma população mais homogênea em relação à idade e/ou tempo que exerce a função possa trazer resultados mais específicos.

Revista Extensão em Foco, nº 20, Jan./Jul. (2020), p. 86 - 101. 


\section{REFERÊNCIAS BIBLIOGRÁFICAS}

AGUIAR, L. U. B.; FIGUEIREDO, F.; OLIVATTO, M.A.; CARNEIRO, M.F.C.; TSCHOEKE, R.; DA COSTA, L.P. Ginástica Laboral: prerrogativa do profissional de educação física. Rio de Janeiro: Sistema Confef/cref, 2015.

ALVES, C. O. Estresse, Qualidade de Vida e Percepção de Suporte Familiar em Porteiros. 134f. Dissertação (Mestrado). Programa de Pós-Graduação em Psicologia do Desenvolvimento e Aprendizagem, Faculdade de Ciências, Universidade Estadual Paulista UNESP, Campus Bauru, 2008.

BITTENCOURT, J.D.C.; CAMPOS, C.M.; EVANGELIST, J.N.; OLIVEIRA, T.S.; SANTOS, C.L.; FERRAZ, D.D. Qualidade De Vida Dos Funcionários De Uma Empresa De Comunicação Impressa Praticantes Da Cinesioterapia Laboral Compensatória. Revista Pesquisa em Fisioterapia, ago;4(2), p.114-122, 2014

CARDOSO, J.P.; RIBEIRO, I.Q.B.; ARAÚJO, T.M.; CARVALHO, F.M.; REIS, E.J.F.B. Prevalência de dor musculoesquelética em professores. Rev Bras Epidemiol. 2009; 12(4): 604-14

FERNANDES S. C.; COUTO G. R. C.FERNANDES D. ; FERREIRA P. Distúrbios osteomusculares relacionados ao trabalho autorreferidos por profissionais de saúde de um hospital em Portugal. Rev Bras Med Trab. 2018;16(3):353-9

FREITAS, Kate Paloma Nascimento et al. Lombalgia ocupacional e a postura sentada: efeitos da cinesioterapia laboral. Revista Dor, São Paulo, v. 4, n. 12,p.308-313, out. 2011.

HELOANI, R. O trabalho do jornalista:estresse e qualidade de vida. Interações, vol. Xll, núm. 22, julho-dezembro, 2006, pp. 171-198 Universidade São Marcos São Paulo, Brasil

IACKSTET, L,; GONÇALVES, A.C.B.F.; SOARES, S.F.C. Análise dos benefícios da cinesioterapia laboral a curto, médio e longo prazo: uma revisão de literatura. Archives Of Health Investigation, v. 7, n. 5, p.168-173, jun. 2018.

MACIEL, A.C.C.; FERNANDES, M.B.; MEDEIROS, L.S. Prevalência e fatores associados à sintomatologia dolorosa entre profissionais da indústria têxtil. Rev Bras Epidemiol 2006; 9(1): 94-102

MADHWANI, K. P.; NAG, P. K. Intervention on Office Ergonomics: A Unique Technique for Prevention of Musculoskeletal Discomfort in Global Corporate Offices. Indian J Occup Environ Med. 2017 Jan-Apr; 21(1): 18-22.

MALlMANN, C. S.; PALAZZO, L. S.; SANDRA, C.; AERTS, D. R. G.C. Fatores associados à síndrome de burnout em funcionários públicos municipais. Psicologia teoria e prática, São Paulo, v.11,n.2, p. 69-82, dez. 2009

Revista Extensão em Foco, nº 20, Jan./Jul. (2020), p. 86 - 101. 
MELO V. F.; Barros I. M.; Freitas N. A. B.; Luzes R. Incidência de distúrbios osteomusculares relacionados ao trabalho (dort), em trabalhadores do setor administrativo do instituto nacional de metrologia, qualidade e tecnologia (inmetro), rio de janeiro, brasil. Revista Saúde Física \& Mental- UNIABEU v.2 n.1 Janeiro - Julho 2013

MOAZZAMI, T. D.; Taghdisi, M. H.; Soltanian, A., Effect of an Ergonomics-Based Educational Intervention Based on Transtheoretical Model in Adopting Correct Body Posture Among Operating Room Nurses, Global Journal of Health, v.8, n.7, p.26-34, jul. 2016.

MORO, A.R.P.; REIS, P.F. A importância da manutenção de bons níveis de flexibilidade nos trabalhadores que executam suas atividades laborais sentados. Universidade Federal de Santa Catarina. Revista Produção. Vol. 3, n. 2003.

OLIVEIRA, J. R. G. A importância da Ginástica Laboral na prevenção de doenças ocupacionais. Revista de Educação Física 2007;139:40-49. Sorriso - MT - Brasil. Faculdade Centro Mato-Grossense Sorriso - MT - Brasil.

PINHEIRO, C.R.; LIPP, M.E.N. Stress Ocupacional e Qualidade de Vida em Clérigos (as). Boletim Academia Paulista de Psicologia, São Paulo, vol.29, n.1, p.126-14. jun. 2009

POBLETE, C. F. M.; LÓPEZ, J. J. V. Asociación entre puesto de trabajo computacional y síntomas musculoesqueléticos en usuarios frecuentes. Med Segur Trab (Internet) 2012; 59 (227) 98-106

SANTOS, G.J.A. Implementação e avaliação de um Programa de Ginástica Laboral: efeitos nos níveis de burnout e nos sintomas musculoesqueléticos. Dissertação (Mestrado em Educação Para a Saúde). Departamento de Educação, Escola Superior de Tecnologia da Saúde de Coimbra, Coimbra, 2017.

SANTOS, A. F.; ODA, J. Y.; NUNES, A. P. M.; GONÇALVES, L.; GARNÉS, F. L. S. Benefícios da ginástica laboral na prevenção dos distúrbios osteomusculares relacionados ao trabalho. Arquivos de Ciências da Saúde Unipar, Umuarama, v. 11, n. 2, p. 99- 113, maio/ago. 2007

SOARES, R. G.; ASSUNÇÃO, A. A.; LIMA, F. P. A., A baixa adesão ao programa de ginástica laboral: buscando elementos do trabalho para entender o problema. Revista Brasileira de Saúde Ocupacional, São Paulo, v.31, n.114, p.149-160, 2006.

SOUZA, L.M.C. Qualidade De Vida e Estresse Na Gênese De Transtornos De Ansiedade Em Plantonistas Da Fundação De Atendimento Socioeducativo De Pernambuco, Brasil. Dissertação (Mestrado em Psicologia Social Organizacional). Instituto Superior de Línguas e Administração de Leiria. Vila Nova de Gaia, 2014.

Revista Extensão em Foco, nº 20, Jan./Jul. (2020), p. 86 - 101. 